\title{
The Ageing Workforce: Policy Dilemmas and Choices
}

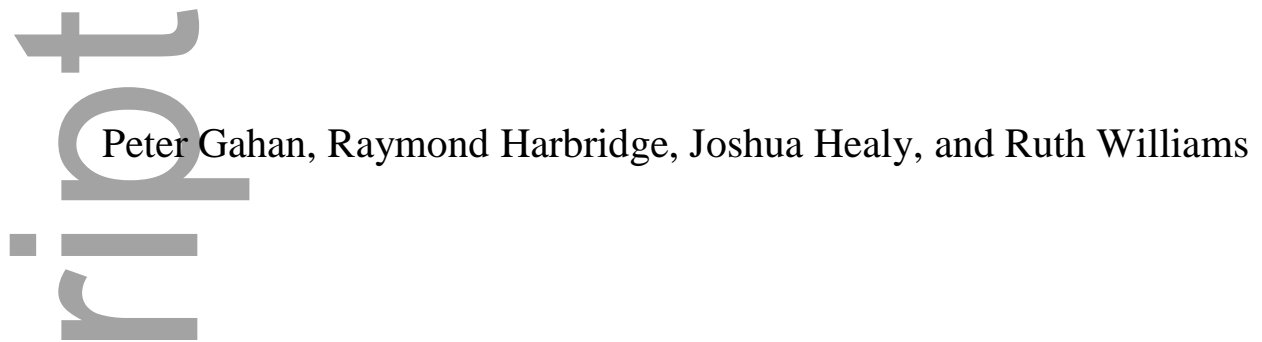

\section{Abstract}

Population ageing is profoundly challenging the institutions and systems that organise paid work, healthcare, and retirement. A major response to these challenges has been to encourage older workers to remain longer in employment, thereby extending the period of 'productive life' in which they are net contributors to government revenue. Yet this strategy depends on a range of micro-leyel adjustments, about which relatively little is known. These include how willingly older workers and employers adjust their attitudes and practices, and what types of policies facilitate these adjustments. In this paper, we critique the major policy responses to workforce ageing in Australia to date, and consider further measures to improve recruitment and retention of older workers. We argue that a more holistic policy response will require better evidence about ageist employment barriers, late-career transitions, and older workers' job performance. We outline a research agenda to improve evidence and policy in these areas.

Keywords: ageing, older workers, employment policy

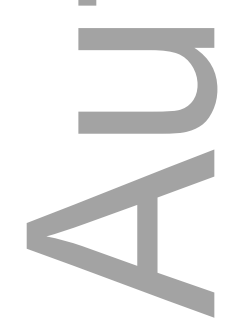

This is the author manuscript accepted for publication and has undergone full peer review but has not been through the copyediting, typesetting, pagination and proofreading process, which may lead to differences between this version and the Version of Record. Please cite this article as doi: 10.1111/1467-8500.12232.

This article is protected by copyright. All rights reserved. 


\section{Introduction}

The world's population is in the middle of a major demographic shift associated with ageing. By 2050, the number of people aged 60 years and over will more than double, to approximately 2 billion, representing around 20 percent of the world's population (United

Nations, 2013). To varying degrees, ageing societies are struggling to meet the needs of their increasingly older populations while contending with the slower labour force and economic growth rates that ageing brings (Maestas et al., 2016). These twin challenges are currently being felt most acutely in developed countries. Projections indicate, however, that in the next half century many developing economies in Asia, Africa and South America will face similar challenges as their populations expand and age (United Nations, 2014).

Australia has contributed to the 'greying' of the developed world's population. Between 1970 and 2014, the share of people aged 60 years and over in Australia's total population increased from 12 to 20 percent (OECD, 2016b). One result has been a steadily rising dependency rate, with fewer working-age Australians (15-64 years) for each person of pension-eligible age (65 years and over). The economic impact of these developments has been offset somewhat by older Australians' rising labour force participation rates. In the past decade, the participation rate of 55-59 year olds rose from 65 to 73 percent, and that of 60-64 year olds from 43 to 54 percent (OECD, 2016a). Yet, older workers aged 55-64 years currently make up less than 15 percent-of Australia's total labour force (ABS, 2016). Their contributions as workers remain under-utilised, especially with increasing life expectancy and better health in older age.

Many of Australia's current population and labour market policy settings expect or encourage a continued increase in labour force participation among older Australians. If this is to occur, it will require wide-ranging policy reforms to accommodate an increasingly older workforce. Greater thought will need to be given (by governments, employers, researchers, and others) to 
viable strategies for recruiting, retaining, re-engaging and, where necessary, retraining older workers for different roles. Organisations will need to recognise and manage new challenges relating to age discrimination, occupational health and safety, succession planning, requests for flexible work, and so on. The implications for government policy are broader still, including aspects of health, housing, transportation, welfare, and superannuation.

We do not canvass all of these issues at length in the current paper. Instead, we focus on the set of dilemmas and choices that confront Australian governments in the employment policy domain. Over the last decade, Australian governments have begun to acknowledge the scale and scope of workforce ageing, principally in the four Intergenerational Reports (Australian Government, 2002, 2007, 2010, 2015). Yet, the policy responses to ageing thus far have been beset by difficulties and disappointments in implementation and take-up. We argue that some of these problems stem from a lack of understanding about the behaviours and preferences of older workers and employers. Evidence about the micro-level responses to macro-level policy initiatives is scant. We highlight several areas in which greater understanding of these issues would facilitate better policy design and implementation.

\section{Australia's ageing workforce}

The composition of Australia's population has changed markedly in recent decades, broadly in line with international trends for the developed economies. The median age has increased, as the population distribution shifts steadily further away from younger and toward older age groups. Population ageing has in turn affected the composition of Australia's workforce.

Figure 1 provides a long-term picture of the population age structure in Australia. The shares of the total population for five broad age groups are shown, for the period from 1950 to 2014 . During the 1950s and 1960s, there was no sustained increase in the proportion of Australia's population aged 65 years and over. The large 'baby boomer' cohort is evident in the share of 
the population aged less than 15 years in 1960. Beginning in the 1970s, however, and accelerated today by the ageing of the baby boomers, Australia's population structure has become progressively older.

Since 1970, the share of the population aged less than 15 years has fallen by 10 percentage points, to 19 percent, while the share aged 55 years and over has increased by nearly the same amount, to 26 percent. In 1999, the number of Australians aged 55 years and over exceeded the number aged less than 15 years for the first time. This trend is expected to continue: the median age will rise from its present 37.3 years to between 41.0 and 44.5 years by 2061 (ABS, 2012).

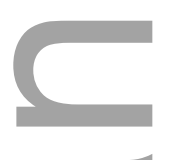

$<$ Figure 1 here>

One way to gauge the extent of population ageing is to compare the ratio of working-age to non-working-age people at different points in time. For this purpose, people of working-age are usually defined as those aged 15-64 years, while people of non-working-age are 65 years and over. The ratio between these two age groups has been in progressive decline for several decades. In Australia, in 1970, there were 7.5 people of working age for each person eligible for the pension. By 1990, the ratio was 6.0 and by 2010 it was 5.0. The latest figures for 2013 put the ratio at $4.6(\mathrm{OECD}, 2016 \mathrm{~b})$.

Internationally, Australia is in a relatively fortunate position. Other developed countries have had to confront the effects of population ageing much sooner than Australia. Across all OECD countries, the average ratio of working-age to pension-eligible populations was 4.2 in 2013. In European Union countries, the ratio is just 3.6 (OECD, 2016b). Australia is heading in the same direction as these other countries, but is arriving there at least a decade later, due to a comparatively young population that has been bolstered by years of high (and highly 
selective) immigration. This does not allow Australian policy-makers room for complacency, but it does present the opportunity to learn carefully from other countries' experiences of dealing with the population ageing challenge before us.

Ratios such as those described above are often used to highlight the growing fiscal 'burden' placed on (younger) taxpayers to support a swelling population of (older) pension claimants. When framed this way, the changing age composition appears to put increasingly intolerable strain on younger populations, and generates political pressure for changing existing welfare arrangements. At the same time, it creates a larger and thus electorally more powerful older voting segment, with a shared interest in maintaining or even expanding current entitlements. In recent years, the Australian Government has responded by announcing staged increases in the qualifying age for the Age Pension, lifting the minimum eligibility age from 65 years to 67 years by 2023 . There have been further proposals, as yet not adopted, to increase this age to 70 years, and to change the eligibility criteria, such as by including the value of the family home in asset means tests (National Commission of Audit, 2014: 80-89).

Successive Australian governments have also responded to the 'fiscal challenge' of ageing in other ways: by establishing a compulsory superannuation system to boost private retirement savings; by maintaining a high migrant intake, supporting regional migration, and selecting immigrants based on their employment prospects; and by offering financial incentives, such as the Baby Bonus, to raise fertility rates. While these various measures help to ease some of the fiscal pressures arising from population ageing, they each have costs and complications that limit their impact. For instance, compulsory superannuation savings supplement the Age Pension for most retirees, without replacing it entirely. An extensive review concluded that this would remain the case for the foreseeable future: 'a fully self-funded retirement is likely to remain the province of those who were relatively well off during their working years' 
(Productivity Commission, 2015, p.7). Similarly, Australia's skilled migration program is an imperfect corrective to ageing: immigrants themselves eventually join the older population, and the overall age composition is also influenced by emigration from Australia, over which the government has little control (McDonald and Kippen, 2001). Finally, fertility incentives, such as the Baby Bonus, have succeeded in raising the birth rate, but the 'marginal cost per additional birth' is high and the benefits for government taxation revenue (from higher labour force participation) are both difficult to quantify and slow to materialise (Drago et al., 2011).

Recent years have also seen changing patterns of labour force participation, which complicate the interpretation of working/non-working population ratios. In Australia, the assumption that people aged 65 years and over have permanently left the workforce is increasingly out of step with observed behaviours (Wilkins and Wooden, 2014). The related assumption that people aged 60-64 years are beginning their transition to retirement is also increasingly at odds with reality. Whether because of changing preferences, circumstances or needs, older Australians are staying in the workforce today for longer than they did in the past. Through additional labour supply and output, their decisions to keep working are easing some of the fiscal burden on government implied by an older population. The benefits are substantial: Deloitte Access Economics (2013) estimated that a five percentage point increase in the labour force participation rate of Australians aged 55 years and over would add $\$ 48$ billion (or around 3\%) to Gross Domestic Product (GDP). This benefit equates to about half of the expected increase in combined government expenditures on health, aged care services and the Age Pension by 2060 (projected to be 6\% of GDP) (Productivity Commission, 2013).

Table 1 shows how Australian labour force participation rates by age and sex have changed between 1985 and 2015. Over this 30-year period, the percentage of older Australians (aged 55 years and over) who are participating in the labour force climbed from 22 to 35 percent. 
This aggregate change was underpinned by even larger changes within specific age groups. Among those aged 60-64 years and 65 years and over, participation rates have more than doubled since 1985 . For the oldest group, this reflects a large change from a low base $(5.1 \%$ in 1985 to $12.2 \%$ in 2015), but the increase is still economically significant. Among 55-59 year olds, participation rates increased by 20 percentage points over the past 30 years, to 73 percent in 2015. Today's older Australians are engaging with the paid labour market to a much greater extent than their predecessors.

\section{<Table 1 here>}

The changes in older women's labour force participation rates have been especially dramatic. Between 1985 and 2015, there was an almost three-fold increase in the participation rate of Australian women aged 55 years and over. The participation rate quadrupled among women aged 60 years and over. It is notable that during this 30-year period, there was no net change in participation rates among younger women aged 15-24 years. Much of the recent increase in Australian female participation rates has thus been driven by older women's behaviour. This change stems from several factors, including higher divorce rates, lower lifetime earnings due to a persistent gender pay gap, and lower female retirement savings due to spells out of paid employment (McGann et al., 2016).

It is not only that older Australians are entering the labour force in larger numbers; they are also taking a larger share of the full-time jobs. In 1985, 9 percent of the full-time jobs were held by people aged 55 years and over. Thirty years later, in 2015, their share had risen to 17 percent. This change has coincided with a large decline in the share of full-time jobs held by younger workers (aged less than 30 years), from 38 percent in 1985 to 24 percent in 2015 (ABS, 2016). Rightly or wrongly, these compositional shifts feed a perception that older workers are blocking avenues into the workforce (and especially into higher-prestige jobs) for 
young jobseekers (Rayner, 2016). This perceived intergenerational competition for status and resources represents another edge to the policy challenges around ageing (North and Fiske, 2013).

The foregoing discussion shows that Australia's workforce has changed, and will continue to change, due to the effects of ageing. Major policy initiatives, such as compulsory superannuation, have anticipated this process and have helped to cushion some of its effects. Behavioural changes have also occurred as working beyond the customary retirement age has become possible - and more desirable - for older Australians.

The next frontier in population ageing policy and research is to ensure that older Australians who want to continue working are able and encouraged to do so, in ways that maximise both their personal satisfaction and their economic contributions. Progress on this front requires that policy-makers understand a host of different issues that have largely been obscured by the macro-level focus on dependency ratios, Age Pension eligibility rules, and inducements for private retirement saving. The economic 'dividend' from reforms in those areas has been largely exhausted by initiatives already implemented or planned. The next phases of reform will involve broaching less-studied, micro-level issues. What motivates older Australians to keep working or retire? How do employers' practices help or hinder these choices? And, in a climate of increasing intergenerational tension, what are the impacts on opportunities for younger workers of older workers postponing their retirement? It is to these and other issues that we now turn.

\section{Older workers and their employers}

A micro view of older workers is important, as it introduces new dimensions to the policy debate; it is not just about securing labour supply. We introduce two main issues here. The first relates to older workers' motivations, which are shaped by their work experiences, job 
demands, opportunities, and other preferences. The second issue is the need to effect social change by addressing prejudicial attitudes towards older workers. Meta-analyses consistently show that older workers' colleagues and managers hold deleterious stereotypes about them (Ng and Feldman, 2012; Posthuma and Campion, 2009). These issues involve some different policy challenges and open up new possibilities for action.

Another important issue - although not one that we seek to resolve - is the meaning of an 'older worker'. Ageing in the workplace context almost certainly implies different experiences and expectations than those associated with 'the elderly' and 'aged care' in the wider population. Much of the research defines an older worker as someone older than 50 or 51 years (Karoly and Zissimopoulos, 2004). Yet there is wide variation around this cut-off in some definitions. Within OECD countries, public policies typically have thresholds of around 55 years or older, depending on the age of eligibility for pension entitlements. Some studies adopt 55 years, due to the observed tendency for labour market participation rates to decline after that age (Kooij et al., 2008). Others use younger thresholds, closer to 40 years, as the age at which 'career development' ends and 'career maintenance' begins ( $\mathrm{Ng}$ and Feldman, 2008). Contemporary research finds that workers are regularly thought to be 'older' by the time they reach 45 years (Thomas et al., 2014). There are also likely to be differences by industry, depending on the physicality of particular jobs. These definitional differences affect how we think about the 'burden' of ageing, and how debates about intergenerational inequalities are framed.

Crucially, chronological age does not solely determine who is an 'older worker' - or who is seen to be. Instead, it serves as a proxy for 'a broad range of age related processes that exert diverse and indirect effects on work outcomes' (Kanfer and Ackerman, 2004). Other relevant factors include a person's health, the composition of their particular workplace or profession, 
and organisation-specific norms relating to tenure, succession and retirement (Posthuma and Campion, 2009). Different age possibilities modelled by Sterns and Doverspike (1989) included functional age (physical appearance and biological changes), psychosocial age (subjective assessments of how old a person appears to be), organisational age (retirement planning and career-stage), and lifespan age (indicators based on a person's interests or life circumstances). Using those possibilities, McCarthy et al. (2014) undertook a large survey of organisational leaders in Ireland and found that their perceptions of 'older' varied by as much as 10 years (from 48 to 58 years), depending on how age was conceptualised. This variability means that it is entirely possible for 60 year-olds to avoid the negative age biases that affect 50 year-olds in different circumstances.

Older workers confront age-related stereotypes most acutely when they are looking for work after retrenchment. These jobseekers often face multiple disadvantages, arising not only from their age but also from other factors, including the loss of occupational networks, skill and physical health limitations, and local labour market difficulties (Gallo et al., 2000). The barriers to re-employment can be so severe that, when coupled with the initial discouraging effects of job loss, displaced workers give up looking for work altogether (Gregory, 2012). Transitional assistance to displaced workers is therefore critical, and the extension of this assistance to older workers will become more important as technological disruption encroaches on higher-skill sectors of the economy (Susskind and Susskind, 2015). It is important to recognise, however, that even older workers with specialist skills can find their prospects hampered by involuntary job loss. Using the example of aviation workers made redundant by the Ansett Airlines collapse, Weller (2007) shows that subtle employer preferences can impede the re-employment of older job-losers, even when their skills appear to be in high demand. Many former Ansett workers had 'highly tradeable technical skills' and other, newer airlines were looking to recruit. Yet, older Ansett workers were not seen to fit 
with the youthful image and 'overtly sexualised expectations' of the newer firms (Weller, 2007). Problems often stem from a failure on the part of employers to even consider hiring workers who do not 'look right' for a job, including judgments based on applicants' age (Shacklock et al., 2007; Warhurst et al., 2009).

Assumptions about age-related behaviours and competencies, however faulty, also shape how older workers experience the transition to retirement. Some are fortunate: their organisations have put in place policies that are responsive to changes in circumstances and preferences, and that offer respect and choice in how these changes are handled (Hennekam and Herrbach, 2015). Such organisations are likely to have considered work expectations, job-related skills and competencies, options for 'bridge' employment, and manifestations of underlying ageism (Truxillo and Fraccaroli, 2013). Re-training opportunities are vital for older workers to avoid skills obsolescence, particularly in industries beset by technological disruption (Lazazzara et al., 2013). The management of work stress is also important; older workers are more likely to engage in bridge employment when they have experienced lower levels of stress (Wang et al., 2008). Other types of support and accommodation may also be beneficial for older workers in physically-demanding roles (Timmons et al., 2011).

In addition to the above considerations, much evidence on organisational responses to ageing emphasises the need for managers and work roles to be 'flexible'. Organisations appear to be more successful in retaining older workers when work obligations are organised and managed around non-work roles and responsibilities - these include personal health difficulties, caring commitments, volunteering and study (Bal and Dorenbosch, 2015). A recent Australian study underscores the importance of flexible work arrangements in facilitating 'staged' retirement and reducing the probability of permanent early exit for older workers (Kalokerinos et al., 2015). Ideally, flexibility should enable both reductions and increases in work hours. 
Stepping down from full-time to part-time work is a common way to achieve flexibility, yet many older workers in part-time positions want more hours and feel trapped in a cycle of under-employment (Li et al., 2015).

While prior research offers guidance about the workplace practices that promote retention of older workers, evidence of their actual prevalence is less developed. In the United Kingdom, Barnes, Smeaton and Taylor (2009) identified three areas in which some employers were starting to take action: 'pro-age' policies, flexible work, and managing older workers' health issues. Progress in these areas was unevenly spread across industry sectors and organisations. Pro-age polices were generally associated with larger organisations, a more professionalised staff, higher union density, and higher female representation in the workplace. Strategic age management policies were less likely to exist in workplaces dominated by blue-collar staff.

The Australian Government recognised the importance of flexible work arrangements when, in July 2013, it extended a 'right to request' these arrangements to older workers aged 55 years and over. Employers must consider each request on its merits, explore all possibilities to accommodate the needs of the staff member and their work unit, and explain and justify any decision, while observing equal opportunity laws (Fair Work Ombudsman, 2013). While this right now exists for older Australian workers, its operation is difficult to monitor and enforce. In many organisations, flexible work arrangements are seen as matters of managerial discretion, and requests may become problematic when some managers have more leeway than others to exercise their discretion. Decisions may be exposed to personal differences and perceptions of discrimination (Williams, 2015).

\section{Australian Government policies on the ageing workforce}

Public perceptions of ageing are still subject to considerable misunderstanding arising from persistent myths and stereotypes. Policy initiatives reflect the fact that ageing is often framed 
as a distributive or allocative problem, such as the perceived 'burden' on younger workers, or taxpayers generally, to support an older population. Too often, major policy statements about ageing are framed for short-term political advantage as much as for long-term strategic planning purposes. A prominent example is the recent Intergenerational Report (Australian Government, 2015), which was released shortly before the 2015 Budget and described as 'heavily laced with politics' (Grattan, 2015) and 'weighed down with imagined economic assumptions made for partisan political reasons' (Jericho, 2015).

The development of government policies to support older workers who choose to stay in the workforce for longer, or re-enter it sooner after a temporary absence, will be key to continued economic growth. The Australian Government recognises the benefits of higher labour force participation, and has sought to 'encourage those currently not in the workforce, especially older Australians and women, to enter, re-enter and stay in work, where they choose to do so' (Australian Government, 2015, p. iii). Targets have been set for increasing participation rates of those aged 65 years and over from around 12 percent at present (see Table 1) to 17 percent by 2055 (Australian Government, 2015). An increase in older labour force participation of this magnitude would deliver a substantial increase in economic output (Chomik and Piggott, 2012; Productivity Commission, 2015). But achieving it will require more than exhortations and changes to Age Pension rules. It will also require a sustained policy reform commitment, backed by a much improved understanding of the micro-level issues that affect older workers' choices.

Moves to increase the Age Pension qualifying age have drawn attention to other complicating issues. The Productivity Commission (2013) noted that some policies 'distort the choices and attitudes of both employers and employees towards participating in the labour market and have wider fiscal and other impacts on the wellbeing of Australians'. These include barriers 
to mature-age employment, such as physical and mental health constraints, a lack of suitable work, diminished opportunities for learning, and discriminatory human resources practices. Expanding education and training programs for older workers is seen as an essential lever to encourage their participation (Australian Institute of Management, 2013).

To date, the Australian Government's main attempt to overcome some of the barriers to older workforce participation has been the Restart program. Introduced in the 2014 Budget, and commencing on 1 July 2014 , this initiative offered financial incentives of up to $\$ 10,000$ for employers to take on older workers (aged 50 years and over) who had been receiving income support (including the Age Pension) for a minimum of six months. The subsidy was available to employers who hired an eligible older jobseeker on a full-time basis (30 hours or more per week). Despite this financial incentive, take-up rates have been decidedly low and the scheme has been derided as 'a dismal failure', 'falling spectacularly short of its target' (Gartrell, 2015; Opray, 2015). Department of Employment documents reveal that just 1,735 people out of an expected 35,000 made use of the Restart scheme in its first year.

Shortly after these criticisms, the scheme's evaluation, which was due to occur in June 2016, was brought forward to find ways of boosting take-up. Criticisms of Restart included that it was administratively cumbersome and of insufficient value to entice larger employers, given the lengthy application process. The scheme's eligibility criteria were also seen as restrictive. If organisations were able to select their own mature-age recruits, this would perhaps increase interest; however, it would also dilute the scheme's main intention to bring welfare claimants back into employment. Another limitation, common to wage-subsidy schemes, is the 'stigma' effect: such schemes send prospective employers a negative message about hiring from the target group, and may entrench existing biases (see Billett et al., 2011). In this case, payments through Restart imply that returning older workers are not likely to be sufficiently productive 
for employers to hire them independently of government assistance. This (implied) message contrasts sharply with other efforts to represent older workers as valuable assets, due to their accumulated experience, skills and organisational memory. Finally, the Restart scheme did not address underlying sources of age discrimination, which the recent Willing to Work Inquiry identified as 'a significant concern' and one of the chief barriers to older workforce participation (Australian Human Rights Commission, 2016: 38).

\section{Toward a more holistic policy agenda}

The economic and personal benefits of extending paid workforce participation are potentially large. They include reduced social welfare obligations for governments, higher organisational productivity through retention of skills and tacit knowledge, and greater personal fulfilment for older workers who are able to continue contributing to a workplace or vocation. On the other hand, postponing retirement for larger numbers of older workers will also create new costs and challenges that need to be understood and managed. These costs include difficulties associated with overcoming entrenched biases about older workers' capabilities, ensuring that older workers are able to maintain their physical health and technological proficiency in order to remain productive, and possible resistance to lengthier careers from some groups, such as older non-professional workers and younger workers who see themselves in competition with older workers for higher-status jobs. Responses to workforce ageing must take account of the changing nature of jobs and work participation. The disappointments of previous government initiatives in this area point to a lack of understanding about the organisational and individual experiences of older workers. A better-targeted research agenda will assist in identifying new initiatives that are more likely to encourage older workforce participation. Our suggestions of the most promising directions for this new research agenda follow. 
Underlying barriers to older workers' participation must be understood and challenged, such as persistent age-related biases and stereotypes. Much of the evidence on ageism is based on convenient but unrepresentative samples, such as undergraduate students (e.g., Fraboni et al., 1990; Lin et al., 2011) or online freelance workers (e.g., North and Fiske, 2013). There have been relatively few attempts to study the population prevalence of ageism, and even fewer studies that track ageist attitudes at the population level over time. Consequently, little is known about whether negative attitudes towards older people have evolved or dissipated, and why. Further, while there are numerous general studies of age prejudice, few examine the specific determinants of stereotypical attitudes and/or discrimination against older people in the context of employment.

Stereotypes seem to persist, even though age discrimination has long been legally proscribed. This suggests that legislative changes will not suffice to shift entrenched biases about older workers' (Blackham, 2016), much as equal pay laws did not eliminate the gender pay gap (Borland, 2014). There is a noticeable lacuna in the literature on how ageist stereotypes lead to adverse treatment of older workers and older job applicants. Negative behaviours may be manifest during recruitment or during employment, in remuneration, performance appraisals, access to training, and so on. Our understanding of these processes in respect of age lags well behind the corresponding literatures focused on gender and race.

The negotiation of late career transitions, especially from work to retirement, has received some attention, with a focus on barriers. Related to this are the ways that organisations seek to accommodate older workers in order to retain them. Both issues serve to highlight the fact that we have only limited understanding of what older workers themselves are likely to want in making late career transitions, including the timing and phasing of transition to retirement, and from work itself. We might expect these preferences to be shaped by a range of factors. 
Yet, there are no established conceptual frameworks on which to base empirical research. Developing appropriate explanatory frameworks that assist in sequencing empirical work is therefore a major research imperative.

More broadly, researchers have shown a growing interest in understanding how individuals negotiate shifts in 'social identities' as their personal circumstances change, especially where such shifts undermine or destroy social roles that have previously been dominant in shaping one's sense of self. This body of research highlights how individuals attempt to rework old identities, reconcile lost identities, and resist stereotypes associated with new identities (e.g., Hubble, 2013; McAdams and Olson, 2010; Schafer and Shippee, 2010). This process has received little attention in the context of changing work roles as a source of identity formation for older workers.

Research around mature-age employee performance is also increasingly dated and its range is limited, particularly the Australian evidence. Revisiting this issue may help to reveal different patterns and insights attributable, for example, to significant recent shifts in automation and digitisation across sectors. Until recently, the economics literature has been dominated by the notion of skill-biased technological change; more recently, work has highlighted the fact that 'smart technologies' have altered the skill content of jobs in complex ways that have been associated with the redundancy of higher-skilled jobs (Ford, 2015). This suggests the need to consider how technological changes, and new business models enabled by technology, may alter the capacities of people with different skill-sets. Some of this may be related to age and could thereby influence the relationship between age and job performance. The justification for revisiting mature-age work performance is also connected to growing workforce diversity, which has included increasing age-based diversity within workplaces and teams. Here again, 
it is not clear from prior research how or whether different age cohorts adjusted effectively to working in teams characterised by greater age diversity.

Retention and engagement of older workers presents a major business and public policy imperative. Established employment and HR practices need to reflect the changing nature of work and a changing workforce composition. For example, an ageing workforce profile may necessitate job redesign to maintain person-job fit over longer working lives. Retention of older workers may also require different types of HR practices and access to flexible work arrangements that enable older workers to balance different forms of work-life demands. Similarly, the management of work teams and leadership styles may also require adjustment to reflect increasing age-diversity and the need for more inclusive workplace cultures.

There is little empirical work examining how organisations are innovating around these types of issues, and how these adjustments impact on organisational and individual-level outcomes. Given the observed reluctance of most organisations to take a more proactive or strategic approach to ageing, understanding what works and why in different contexts is a vital area for new research. Further, while prior studies have identified a variety of pro-active policies that can encourage older workforce participation, these policies are largely untested in Australia.

\section{Conclusion}

Over coming decades, the issue of how to retain older workers in productive employment will be one of the most significant policy issues facing governments and organisations. The ageing workforce presents many new challenges, as larger cohorts of older workers negotiate the transition from prime-age to late-careers and ultimately into retirement. To date, government policies to maintain and encourage mature-age labour force participation have fallen well short of expectations, highlighting a need for better understanding and new approaches. 
A broad range of interconnected policy adjustments is needed. The most prominent issues in Australian policy discussion have been those relating to retirement incomes, including pension eligibility, superannuation taxation arrangements, and associated welfare and equity effects. We have argued that the ageing workforce necessitates policy alignment across a significantly wider set of issues. These include active labour market policies that assist older workers displaced by industry restructuring, policy innovations that support increasingly varied late-career transitions, workplace health and safety measures, and best-practice initiatives that allow organisations to benefit from greater workforce age diversity and greater flexibility in working arrangements. Policies on older workers should also be designed with attention to their collateral impacts, such as their regional dimensions and their consequences for younger workers' opportunities.

More generally, evidence-based policy-making must be adaptive and guided by timely evaluations of new initiatives. Progress could be achieved by pilot-testing some of the novel proposals put forward already by organisations such as Per Capita (2014) and the Australian Human Rights Commission (2016). More routine and transparent data collection is essential for meaningful policy development (Baldwin et al., 2015). Within government, multi-agency involvement will also assist in sharing data and learning from prior policy experience (Adams et al., 2015; Head, 2015).

In this paper, we have outlined the major policy dilemmas and choices arising from an ageing workforce, and pointed to some of the gaps in understanding that impede effective responses to it. A more holistic policy framework, of the kind we propose, is urgently needed.

\section{References}

Adams, D., Colebatch, H., and Walker, C. (2015) 'Learning about learning: Discovering the work of policy'. Australian Journal of Public Administration, 74(2): 101-111. 
Australian Bureau of Statistics (ABS) (2012) Population Projections, Australia, 2012 (base) to 2101. Cat. no. 3222.0, Canberra.

Australian Bureau of Statistics (ABS) (2016) Labour Force, Australia, Detailed - Electronic Delivery, December 2015. Cat. no. 6291.0.55.001, Canberra.

Australian Government (2002) Budget 2002-03 Budget paper no 5: Intergenerational Report. Canberra: The Treasury.

Australian Government (2007) Intergenerational Report 2007. Canberra: The Treasury.

Australian Government (2010) Australia to 2050: Future Challenges. Canberra: The Treasury.

Australian Government (2015) 2015 Intergenerational Report: Australia in 2055. Canberra: The Treasury.

Australian Human Rights Commission (2016) Willing to Work: Report of the National Inquiry into Employment Discrimination Against Older Australians and Australians with Disability. Available from: http://bit.ly/1rLWziU

Australian Institute of Management (2013) 'Engaging and retaining older workers', Discussion paper, February. Available from: http://bit.ly/1SBQGdx

Bal, P. and Dorenbosch, L. (2015) 'Age-related differences in the relations between individualised HRM and organisational performance: A large-scale employer survey'. Human Resource Management Journal, 25(1): 41-61.

Baldwin, R., Chenoweth, L. and dela Rama, M. (2015) 'Residential aged care policy in Australia: Are we learning from evidence? Australian Journal of Public Administration, 74(2): 128-141.

Barnes, H., Smeaton, D. and Taylor, R. (2009) An Ageing Workforce: The Employer's Perspective. Brighton, England: The Institute for Employment Studies.

Billett, S., Dymock, D., Johnson, G. and Martin, G. (2011) 'Overcoming the paradox of employers' views about older workers'. International Journal of Human Resource Management, 22(6): 1248-1261.

Blackham, A. (2016) Extending Working Life for Older Workers: Age Discrimination Law, Policy and Practice. Sydney: Hart Publishing. 
Borland, J. (2014) 'The long and slowing road to gender pay equity'. Labour market snapshots. Available from: http://bit.ly/2bvwCfs.

Chomik, R. and Piggott, J. (2012) 'Mature-age labour force participation: Trends, barriers, incentives, and future potential'. CEPAR briefing paper 2012/01, Centre of Excellence in Population Ageing Research, Sydney: University of New South Wales.

Deloitte Access Economics (2012). Increasing Participation among Older Workers: The Grey Army Advances. Report prepared for the Australian Human Rights Commission.

Drago, R., Sawyer, K., Sheffler, K., Warren, D. and Wooden, M. (2011) 'Did Australia's Baby Bonus increase the fertility rate?' Population Research and Policy Review, 30(3): 381-397.

Fair Work Ombudsman (2013). 'Flexible working arrangements'. Melbourne. Available from: http://bit.ly/1NpklW7.

Ford, M. (2015) Rise of the Robots: Technology and the Threat of a Jobless Future. Basic Books: New York.

Fraboni, M., Saltstone, R. and Hughes, S. (1990) 'The Fraboni Scale of Ageism (FSA): An attempt at a more precise measure of ageism,' Canadian Journal on Aging, 9(1): 56-66.

Gallo, W., Bradley, E., Siegel, M. and Kasl, S. (2000) 'Health effects of involuntary job loss among older workers: Findings from the Health and Retirement Survey'. The Journals of Gerontology: Series B, Psychological Sciences and Social Sciences, 55(3): S131S140,

Gartrell, A. (2015) 'Government jobs program falls 95 per cent short of target', Sydney Morning Herald, 8 November. Available from: http://bit.ly/1oqQ5Ut.

Grattan, M. (2015) 'No pressure Joe, but you are back in the spotlight'. The Conversation, 5 March. Available from: http://bit.ly/2bD5sWo

Gregory, R. (2012) 'Dark corners in a bright economy: The lack of jobs for unskilled men'. Australian Bulletin of Labour, 38(1): 2-25.

Head, B. (2015) 'Relationships between policy academics and public servants: Learning at a distance?' Australian Journal of Public Administration, 74(1): 5-12.

Hennekam, S. and Herrbach, O. (2015) 'The influence of age-awareness versus general HRM practices on the retirement decision of older workers'. Personnel Review, 44(1): 3-21. 
Hubble, N. (2013) Ageing, Narrative and Identity: New Qualitative Social Research. Houndmills, Basingstoke, Hampshire Palgrave McMillan.

Jericho, G. (2015) 'Intergenerational Report: Assumptions about government spending are a confusion of idiocy'. The Guardian, 9 March. Available from: http://bit.ly/2bNSvIS

Kalokerinos, E., von Hippel, C. and Henry, J. (2015) 'Job attitudes are differentially associated with bridge employment and phased retirement among older Australian employees'. Work, Aging and Retirement, 1(2): 190-201.

Kanfer, R. and Ackerman, P. (2004) ‘Aging, adult development, and work motivation'. Academy of Management Review, 29(3): 440-458.

Karoly, L. and Zissimopoulos, J. (2004) 'Self-employment among older US workers'. Monthly Labor Review, 127(7): 24-47.

Kooij, D., de Lange, A., Jansen, P. and Dikkers, J. (2008) 'Older workers' motivation to continue to work: Five meanings of age. A conceptual review'. Journal of Managerial Psychology, 23(4): 364-394.

Lazazzara, A., Karpinska, K. and Henkens, K. (2013) 'What factors influence training opportunities for older workers? Three factorial surveys exploring the attitudes of HR professionals'. International Journal of Human Resource Management, 24(11): 21542172.

Li, J., Duncan, A. and Miranti, R. (2015) 'Underemployment among mature-age workers in Australia', Economic Record, 91(295): 438-462.

Lin, X., Bryant, C. and Boldero, J. (2011) 'Measures for assessing student attitudes toward older people'. Educational Gerontology, 37(1): 12-26.

Maestas, N., Mullen, K. and Powell, D. (2016) 'The effect of population aging on economic growth, the labor force and productivity,' Working paper no. 22452, National Bureau of Economic Research, Cambridge, MA.

McAdams, D. P. and Olson, B. D. (2010) 'Personality development: Continuity and change over the life course'. Annual Review of Psychology, 51, 517-542.

McCarthy, J., Heraty, N., Cross, C. and Cleveland, J. (2014) 'Who is considered an "older worker"? Extending our conceptualisation of "older" from an organisational decision maker perspective'. Human Resource Management Journal, 24(4): 374-393. 
McDonald, P. and Kippen, R. (2001) 'The impact of immigration on the ageing of Australia's population', in Siddique, M. (ed.) International Migration into the 21 st century: Essays in honour of Reginald Appleyard, Edward Elgar Publishing, Cheltenham, UK: 153-177.

McGann, M., Ong, R., Bowman, D., Duncan, A., Kimberley, H. and Biggs, S. (2016) A Gendered Analysis of Age Discrimination among Older Jobseekers in Australia. Bankwest Curtin Economics Centre Working Paper 16/01, Curtin University, Perth.

National Commission of Audit (2014) Towards Responsible Government: The Report of the National Commission of Audit, Phase One. Canberra: Australian Government.

Ng, T. and Feldman, D. (2008) 'The relationship of age to ten dimensions of job performance'. Journal of Applied Psychology, 93(2): 392-423.

North, M. and Fiske, S. (2013) 'A prescriptive intergenerational-tension ageism scale: Succession, Identity and Consumption'. Psychological Assessment, 25(3): 706-713.

OECD (Organisation for Economic Co-operation and Development) (2016a)

OECD.StatExtracts, 'Labour force statistics by sex and age'. Available from: http://bit.ly/1UByX8W.

OECD (Organisation for Economic Co-operation and Development) (2016b)

OECD.StatExtracts, 'Population statistics'. Available from: http://bit.ly/1UBz7xa.

Opray, M. (2015) 'Exclusive: Govt plan for older workers falls short', The New Daily, 29 October. Available from: http://bit.ly/1kXnmFj.

Per Capita (2014) Blueprint for an Ageing Australia. Sydney, Per Capita Australia Ltd.

Posthuma, R. and Campion, M. (2009) 'Age stereotypes in the workplace: Common stereotypes, moderators, and future research directions'. Journal of Management, 35(1): 158-188.

Productivity Commission (2013) An Ageing Australia: Preparing for the Future. Canberra: Australian Government.

Productivity Commission (2015) Superannuation Policy for Post-Retirement. Commission Research Paper, Canberra: Australian Government.

Rayner, J. (2016) Generation Less: How Australia is Cheating the Young. Melbourne: Black Inc. Books. 
Schafer, M. and Shippee, T. (2010) 'Age identity in context: Stress and the subjective side of ageing'. Social Psychology Quarterly, 73(3): 245-264.

Shacklock, K., Fulop, L. and Hort, L. (2007) 'Managing older worker exit and re-entry practices: A “revolving door”?' Asia Pacific Journal of Human Resources, 45(2): 151167.

Sterns, H. and Doverspike, D. (1989) 'Aging and the retraining and learning process in organisations'. In Goldstein, I. and Katzel, R (eds.), Training and Development in Work Organisations, San Francisco: Jossey-Bass.

Susskind, R. and Susskind, D. (2015) The Future of the Professions: How Technology Will Transform the Work of Human Experts. Oxford, UK: Oxford University Press.

Thomas, R., Hardy, C., Cutcher, L. and Ainsworth, S. (2014) 'What's age got to do with it? On the critical analysis of age and organizations'. Organization Studies, 35(11): 15691584.

Timmons, J., Hall, A., Fesko, S. and Migliore, A. (2011) 'Retaining the older workforce: Social policy considerations for the universally designed workplace'. Journal of Aging \& Social Policy, 23(2): 119-140.

Truxillo, D. and Fraccaroli, F. (2013) 'Research themes on age and work: Introduction to the Special Issue'. European Journal of Work and Organizational Psychology, 22(3): 249252.

United Nations (2013) World Population Ageing. New York: United Nations.

United Nations (2014) Concise Report on the World Population Situation in 2014. New York: United Nations.

Wang, M., Zhan, Y., Liu, S., and Shultz, K. (2008) 'Antecedents of bridge employment: A longitudinal investigation'. Journal of Applied Psychology, 93(4): 818-830.

Warhurst, C., van den Broek, D., Hall, R., and Nickson, D. (2009) 'Lookism: The new frontier of employment discrimination?' Journal of Industrial Relations, 51(1): 131136.

Weller, S. (2007) 'Discrimination, labour markets and the labour market prospects of older workers: What can a legal case teach us?' Work, Employment and Society, 21(3): 417437. 
Wilkins, R. and Wooden, M. (2014) 'Two decades of change: The Australian labour market, 1993-2013'. Australian Economic Review, 47(4): 417-431.

Williams, R. (2015) Age Management Toolkit for Employers. Melbourne: National Seniors Productive Ageing Centre.

FiguRE 1 - AUSTRALIAN POPULATION SHARES BY AGE GROUP, SELECTED YEARS, 1950-2014

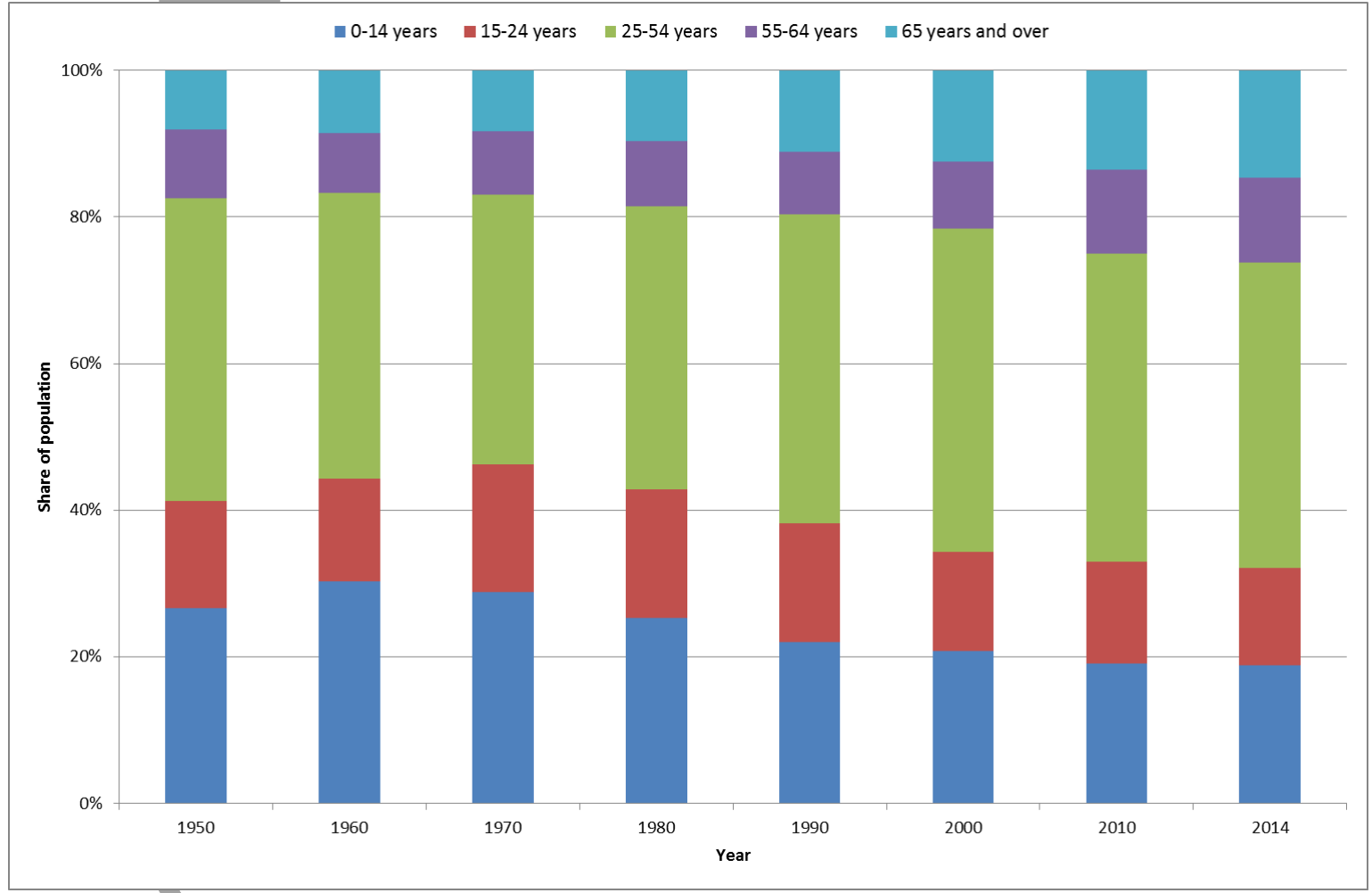

Source: $\operatorname{OECD}(2016 \mathrm{~b})$.

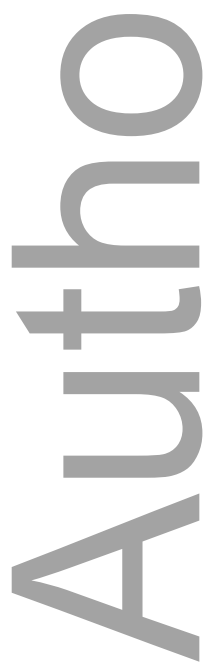


TABLE 1 - AUSTRALIAN LABOUR FORCE PARTICIPATION RATES BY AGE AND SEX, 1985-2015

\begin{tabular}{lrrrrrrr}
\hline$\%$ & 1985 & 1990 & 1995 & 2000 & 2005 & 2010 & 2015 \\
\hline Males & & & & & & & \\
15-24 years & 75.6 & 75.3 & 73.7 & 71.9 & 72.0 & 69.6 & 67.9 \\
25-54 years & 93.4 & 93.3 & 91.7 & 90.2 & 90.3 & 90.6 & 90.3 \\
55 years and over & 36.1 & 34.7 & 32.7 & 33.3 & 37.7 & 42.0 & 41.6 \\
55-59 years & 77.1 & 75.0 & 74.0 & 72.5 & 75.3 & 80.2 & 80.5 \\
60-64 years & 43.8 & 50.6 & 46.9 & 46.6 & 54.3 & 61.5 & 64.1 \\
65 years and over & 9.1 & 9.2 & 9.4 & 9.9 & 11.3 & 15.4 & 16.4 \\
Females & & & & & & & \\
15-24 years & 66.8 & 68.9 & 69.6 & 68.5 & 69.6 & 67.2 & 66.7 \\
25-54 years & 57.3 & 66.8 & 69.0 & 70.5 & 73.7 & 75.1 & 76.6 \\
55 years and over & 10.1 & 11.4 & 12.5 & 15.8 & 21.4 & 27.5 & 29.1 \\
55-59 years & 28.2 & 33.9 & 39.7 & 46.9 & 54.5 & 64.5 & 66.3 \\
60-64 years & 11.9 & 16.0 & 16.1 & 21.5 & 31.2 & 42.7 & 47.1 \\
65 years and over & 2.1 & 2.4 & 2.6 & 3.0 & 4.2 & 6.8 & 8.5 \\
Persons & & & & & & & \\
15-24 years & 71.2 & 72.1 & 71.6 & 70.2 & 70.8 & 68.4 & 67.3 \\
25-54 years & 75.5 & 80.1 & 80.4 & 80.3 & 81.9 & 82.8 & 83.4 \\
55 years and over & 22.0 & 22.1 & 21.8 & 24.0 & 29.1 & 34.4 & 35.1 \\
55-59 years & 53.0 & 54.7 & 57.1 & 59.9 & 65.0 & 72.3 & 73.3 \\
60-64 years & 27.4 & 33.3 & 31.5 & 34.1 & 42.8 & 52.1 & 55.5 \\
65 years and over & 5.1 & 5.3 & 5.5 & 6.0 & 7.4 & 10.8 & 12.2 \\
\hline
\end{tabular}

Source: ABS (2016). Note: Figures are averages for the 12 months of each year. 


\section{University Library}

\section{- M M I E E R VA A gateway to Melbourne's research publications}

Minerva Access is the Institutional Repository of The University of Melbourne

Author/s:

Gahan, P;Harbridge, R;Healy, J;Williams, R

Title:

The Ageing Workforce: Policy Dilemmas and Choices

Date:

2017-12-01

Citation:

Gahan, P., Harbridge, R., Healy, J. \& Williams, R. (2017). The Ageing Workforce: Policy Dilemmas and Choices. AUSTRALIAN JOURNAL OF PUBLIC ADMINISTRATION, 76 (4), pp.511-523. https://doi.org/10.1111/1467-8500.12232.

Persistent Link:

http://hdl.handle.net/11343/292216 